\title{
Étude de quelques aspects de la fabrication des fromages brésiliens Prato et Minas
}

\author{
AVANT - PROPOS \\ par \\ Alan Frederick Wolfschoon POMBO \\ et Múcio Mansur FURTADO
}

\section{INTRODUCTION}

Dans la fabrication des fromages, le rendement est fonction directe de la composition du lait utilisé. Cependant, à part cette composition, d'autres variations peuvent intervenir en raison de la transition "lait $\rightarrow$ caillé " concernant les constituants mêmes du lait au moment de la coagulation. Donc, dans un travail en cours de réalisation dans le DTA/ILCT/EPAMIG, de Juiz de Fora, MG, Brésil, à travers plusieurs données obtenues dans des essais successifs, on envisage :

a) la détermination du rendement prévu dans une fabrication de fromages Prato et Minas, au moyen, soit de formules, soit de calculs arithmétiques ;

b) la détermination des critères des moyens de transition des protéines, de la matière grasse, des sels minéraux et du lactose dans la coagulation du lait par la présure;

c) la détermination de la teneur exacte du lait en matière grasse, correspondant à la teneur de MG sur sec désiré dans le fromage ;

d) de permettre la correction des facteurs agissant sur le rendement final d'une fabrication ;

e) la détermination du pourcentage moyen de réduction de poids des fromages mentionnés, dans la saumure, et, enfin,

f) d'établir la composition moyenne du lactosérum résultant de la coagulation du lait par la présure, dans la fabrication des fromages Prato et Minas.

La littérature brésilienne ne présente pas de chiffres concernant cette étude, ce qui renforce l'importance de la détermination des paramètres mentionnés ci-dessus.

Cette étude présente donc les données préalables sur la compositon physico-chimique du lactosérum des fromages Prato et Minas. 


\section{MATÉRIEL ET METHODE}

Pour cette étude, on a utilisé les lactosérums résultant de la fabrication des fromages mentionnés. Ces lactosérums ont été obtenus conformément à la technique d'élaboration [7] de ces fromages adoptée par le DTA/ILCT/EPAMIG. Les échantillons du lactosérum $(250 \mathrm{ml})$ ont été collectés et analysés immédiatement après la coagulation et le découpage du caillé, et étant, de plus, filtrés avant les déterminations.

Les méthodes analytiques de détermination des composants ont été les suivants: méthode néphélométrique, pour la matière grasse, en utilisant le Milko Tester MK-III (1); la méthode au formol pour les protéines [9]; la méthode de la F.I.L. [2] et aussi une adaptation de la méthode colorimétrique du phénol-acide-sulfurique [10] pour le lactose. Les cendres ont été déterminées sur $10 \mathrm{ml}$ de lactosérum (pesés en bascule analytique) avec un bain de vapeur, incinération du résidu sec (à $550^{\circ} \mathrm{C}$ ), jusqu'à obtention d'une cendre blanche, puis pesée de la cendre en bascule analytique, l'eau étant calculée par différence. Toutes les déterminations ont été réalisées en double.

\section{RESULTATS ET DISCUSSION}

L'importance de bien connaître la composition du lactosérum est due aux divers aspects présentés par ce sous-produit de l'industrie laitière : c'est une source de protéines de grande valeur biologique, ainsi que de lactose ; son contenu en matière grasse est assez considérable et, de plus, il s'agit également d'un problème de contamination ou pollution de l'ambiante.

Les résultats préliminaires de 20 échantillons de lactosérum des fromages Prato et Minas sont présentés ci-après :

\section{TABLEAU 1}

Composition moyenne des lactosérums des fromages étudiés

\begin{tabular}{l|r|r}
\hline Pourcentage & Minas & Prato \\
& & \\
\cline { 2 - 3 } Matière grasse & 0,52 & 0,70 \\
Protéines & 0,75 & 0,73 \\
Lactose & 4,99 & 4,84 \\
Cendres & 0,49 & 0,49 \\
Eau & 93,25 & 93,23 \\
& & \\
\hline
\end{tabular}


Les chiffres présentés ont été obtenus par le procédé classique de coagulation du lait à $32^{\circ} \mathrm{C}$, avec utilisation normale de la présure animale en poudre.

Les pourcentages de matière grasse, dans les lactosérums analysés, ont montré des teneurs de 0,52 et 0,70 p. 100 pour le Minas et le Prato, respectivement; cette différence peut être expliquée par les différents rapports "matière grasse/protéine" existant dans le lait standardisé.

Les autres aspects qui concernent le problème seront discutés plus tard. Les chiffres présentés sont similaires de ceux trouvés dans des publications en d'autres pays $[4,5,8]$ par rapport à d'autres fromages soit des pâtes molles ou des pâtes demi-cuites, de mêmes types.

En utilisant des procédés plus modernes, comme le traitement sous pression, par membranes d'acétate de cellulose (osmose inverse et ultrafiltration), on peut obtenir le lactose ou un concentrat de protéines qui, selon son utilisation ultérieure, présente beaucoup d'intérêt au point de vue alimentaire et économique.

Compte tenu qu'au Brésil la composition du sérum a été très peu étudiée, les chiffres présentés sont importants, car ils pourront être utiles, soit en aidant le contrôle de la fabrication, soit dans l'utilisation du lactosérum pour d'autres buts. Une étude sur l'utilisation et l'incorporation des protéines du lactosérum [6] dans le fromage de Minas a été réalisée récemment dans le DTA/ILCT/ EPAMIG, avec d'excellents résultats. Une autre est en cours de réalisation dans le même Institut en vue de l'utilisation du lactosérum comme matière première dans l'élaboration de boissons réfrigérées de haute valeur calorique [3].

Enfin, il faut remarquer l'importance de l'utilisation de chiffres locaux, qui représentent beaucoup plus la réalité de nos problèmes.

\section{S u m m a r y}

The purposes of a research being done in order to determine the factors involved during the manufacture of the Brazilian cheeses Prato and Minas are here described. Also, the mean values of preliminary determinations of fat, protein, lactose and ash content in wheys from both cheeses are reported. Differences in fat content between wheys were attributed to differences in cheesemaking techniques.

\section{Bibliographie}

[1] A/S Foss Electric - Milko Tester MK III. Instruction Manual (1974). Hillerod, Dinamarca. 
[2] Federaçao Internacional de Laticínios. - Norma FIL-IDF, 28, 1974

[3] Henriques Martins (A. C.) (1977). - Dados não publicados.

[4] Kosikowski (F.) (1977). - Cheese and fermented milk foods. 2 a ed., Edwards Brothers, Inc. Ann Arbor, Michigan, Estados Unidos.

[5] Les LActosérums - Traitement et utilisations (1973). - Association pour la promotion Industrie-Agriculture, 35, rue du Général-Foy, 75008 Paris, França.

[6] Leite (E. A.) (1977). - Dados não publicados.

[7] Mansur Furtado (M.) (1976). - Technologia de fabricação de queijos, publicação do DTA/ILCT - Epamig.

[8] Reyna (R.) e outros (1975). - Sueros de Queseria - Determinaciôn de parametros físico-químicos. ITA, vol. I, 129-148, Argentina.

[9] Wolfschoon (A. F.) e Leite (E. A.) (1977). - A titulação de formol : método rápido para determinação de proteínas do soro. Revista do ILCT, 32 (193), 3.

[10] Wolfschoon (A.F.) (1977). - Determinação de lactose no leite por espectroscopia visível. Revista do ILCT, 32 (191), 19-22. 